Landslides (2018) 15:1631-1644 DOI 10.1007/s10346-018-0977-1 Received: 4 September 2017 Accepted: 13 March 2018 Published online: 27 March 2018 (c) The Author(s) 2018
N. Dixon · A. Smith · J. A. Flint - R. Khanna - B. Clark · M. Andjelkovic

\section{An acoustic emission landslide early warning system for communities in low-income and middle-income countries}

\begin{abstract}
Early warning systems for slope instability are needed to alert users of accelerating slope deformation behaviour, enable evacuation of vulnerable people, and conduct timely repair and maintenance of critical infrastructure. Communities exposed to landslide risk in low- and middle-income countries seldom currently instrument and monitor slopes to provide a warning of instability because existing techniques are complex and prohibitively expensive. Research and field trials have demonstrated conclusively that acoustic emission (AE) monitoring can be an effective approach to detect accelerating slope movements and to subsequently communicate warnings to users. The objective of this study was to develop and assess a simple, robust, low-cost $\mathrm{AE}$ monitoring system to warn of incipient landslides, which can be widely deployed and operated by communities globally to help protect vulnerable people. This paper describes a novel AE measurement sensor that has been designed and developed with the cost constrained to a few hundred dollars (US). Results are presented from physical model experiments that demonstrate performance of the $\mathrm{AE}$ system in measuring accelerating deformation behaviour, with quantifiable relationships between $\mathrm{AE}$ and displacement rates. Exceedance of a pre-determined trigger level of AE can be used to communicate an alarm to users in order to alert them of a slope failure. Use of this EWS approach by communities worldwide would reduce the number of fatalities caused by landslides.
\end{abstract}

Keywords Acoustic emission - Landslides · Early warning $\cdot$ Alarm $\cdot$ Community

\section{Introduction}

Non-seismically induced landslides resulted in over 32,000 fatalities globally between 2004 and 2010 (Petley 2012), with the large majority of these events occurring in Asia and Central and South America, and often involving communities in low- and middleincome countries. Global change (e.g. climate, population, land use and urbanisation) is expected to increase ground instability causing a rise in human and financial direct and indirect losses (Kjekstad and Highland 2009). Early warning of slope failures could significantly reduce humanitarian and economic losses. The UNISDR $(2007,2015)$ has highlighted the impact of landslides and called for development of early warning systems that can be deployed in low-income economies and used to evacuate vulnerable communities before a landslide occurs. Early warning systems (EWS) have been defined by UNISDR (2009) as 'the set of capacities needed to generate and disseminate timely and meaningful warning information to enable individuals, communities and organizations threatened by a hazard to prepare and to act appropriately and in sufficient time to reduce the possibility of harm or loss'. EWS can be classified as alarm, warning and forecasting systems (Stähli et al. 2015). Alarm systems provide a timely alert to people in the immediate vicinity of the landslide (e.g. flashing light and siren) when slope movements cause a pre-determined threshold to be exceeded. In contrast, warning systems are preferred where progressive stages of failures can be identified and an alert can be provided to experts who are responsible to analyse the situation and manage risk by implementing appropriate interventions. Forecasting systems typically produce data that are interpreted by experts on a regular basis usually for a regional scale, with a typical output being danger levels that are made public with a bulletin.

A landslide alarm EWS for use by vulnerable communities in low- and middle-income countries must fulfil the following criteria: be affordable (i.e. low cost); easy to install and use; operate in a range of different site conditions; monitor at appropriate spatial and temporal resolutions; quantify slope deformations (rates) that can pose a risk to the community; be selfsustaining and require minimal human intervention (e.g. autonomous systems for power, data telemetry and processing); networked to transfer information to the user (i.e. the alert); operate in real time; and be robust (i.e. minimal false alerts). Furthermore, an EWS for a community should provide the following four key elements (UNEP 2012):

- A comprehensive assessment of the risks.

- A sensor-based monitoring and warning system.

- A plan for the dissemination of alerts.

- A strategy for the response of the people at risk.

Although numerous types of instrumentation and monitoring techniques are available (e.g. Stähli et al. 2015; Uhlemann et al. 2016; Smethurst et al. 2017), they are currently not widely used for EWS in low- and middle-income countries due to their complexity and high cost. It is more common to use warning and forecasting approaches such as simple rainfall triggers to provide regional information (e.g. Jakob et al. 2012; Martelloni et al. 2012; Lagomarsino et al. 2013). However, these cannot be used to give meaningful, and hence credible, site-specific warnings, with regional warnings liable to be misinterpreted and/or ignored by communities. An example of an appropriate 'low-cost' landslide monitoring solution using surface extensometers is presented by Sassa et al. (2005), although, to date, its use has not become widespread. There is clearly an urgent need for affordable instrumentation for use in landslide EWSs that can be operated by communities (i.e. that engage local people in the 'first mile') and used to trigger implementation of a pre-determined action plan and hence response to save lives.

This paper reports for the first time research to develop a novel simple, robust, low-cost instrumentation based on acoustic emission (AE) monitoring that can be used by communities to receive 


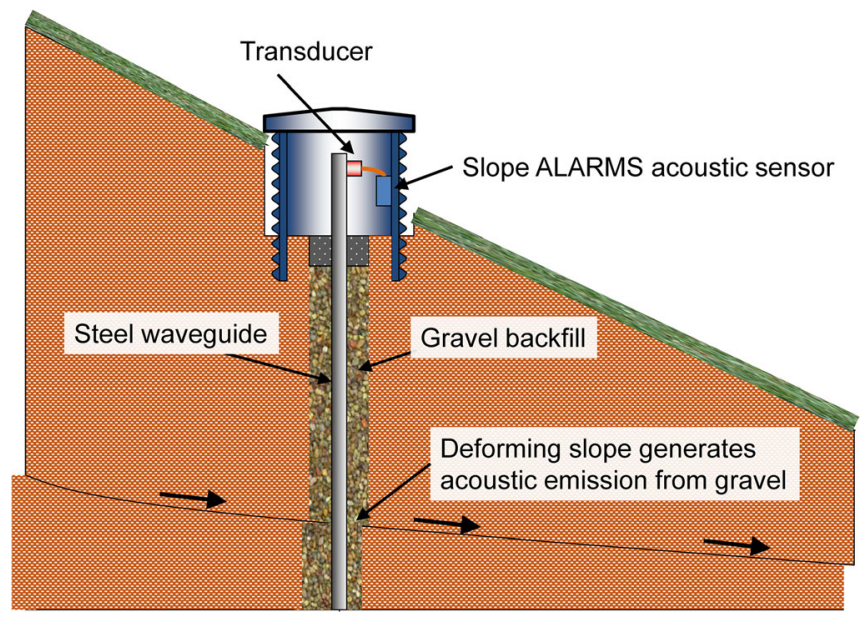

Fig. 1 Slope ALARMS AE monitoring approach incorporating an active waveguide (Dixon et al. 2015)

early warning of landslides and hence protect vulnerable people. The concept of $\mathrm{AE}$ monitoring of slope deformations is introduced; the operation of the Community Slope SAFE (Sensors for Acoustic Failure Early warning) approach is described, and a series of physical model experiments are used to evaluate the performance of this new AE monitoring system. Comparisons are made against established deformation measurement systems with $\mathrm{AE}$ rate vs. displacement rate relationships quantified and a framework for setting trigger levels to generate alerts introduced.

\section{A community acoustic emission slope monitoring system}

\section{AE slope monitoring approach}

Acoustic emissions are elastic stress waves generated by deformation of materials that propagate through the solid phase. They are super audible, and therefore, the frequencies are too high to be detected by the human ear. AE are used in many industries to detect and quantify deformation mechanisms (e.g. crack formation and propagation in aeronautical components, pressure vessels and pipes). In soils, $\mathrm{AE}$ are generated by movement at particle-to-particle contacts and between soil particles and structural elements. AE monitoring is not as well developed in geotechnical monitoring applications as in other industries due to low energy levels of generated $\mathrm{AE}$ and the high attenuation of signals as they propagate through the ground, both of which make it challenging to detect and quantify AE. However, recent research and advances in instrumentation have resulted in successful applications using AE to monitor soil slope stability (Berg et al. 2018; Dixon et al. 2015a, 2015b; Smith and Dixon 2015; Smith et al. 2014, 2017a, c). This body of work has proven that monitoring $\mathrm{AE}$ can be used to provide an early warning of slope instability by detecting both the development of shear surfaces and accelerating deformation behaviour (Chichibu et al. 1989; Fujiwara et al. 1999; Koerner et al. 1981; Michlmayr et al. 2017; Nakajima et al. 1991; Smith et al. 2017a).

\section{Slope ALARMS}

A brief description of the previously developed and established Slope ALARMS system is included below to provide context for development of the low-cost Community Slope SAFE landslide EWS. The
Slope ALARMS approach uses a unitary battery-operated sensor that can monitor AE continuously and in (near) real time, which links wirelessly with a communication node to provide alert messages to nominated persons using a standard mobile telecommunication network. This is categorised as a warning system as information is relayed to professionals who then decide on actions to be taken. A critical component of the approach is the use of an active waveguide installed through the slope to depths below the existing or developing shear surfaces that control stability. An active waveguide comprises a steel tube installed in a pre-drilled borehole with the annulus between the tube and borehole sidewall backfilled with 'noisy' granular materials (i.e. either gravel or sand). The AE sensor is attached to the top of the steel tube and protected by a secure cover (Fig. 1). As the slope moves, in addition to the in situ material generating $\mathrm{AE}$, the backfill material is deformed generating high levels of $\mathrm{AE}$. It should be noted that the system was initially developed to monitor slopes formed in finegrained soils that generate very low levels of $\mathrm{AE}$, hence the need to add noisy backfill material. The AE propagate up the steel tube to the sensor at ground level where they are detected, converted to a voltage signal and quantified. AE attenuation in steel is very low, and hence, $\mathrm{AE}$ can propagate large distances along the waveguide (i.e. many $10 \mathrm{~s}$ m) (e.g. Smith et al. 2017b).

$\mathrm{AE}$ is quantified by counting the number of times the $\mathrm{AE}$ signal exceeds a pre-determined voltage threshold (called ring-down counts (RDC)). The threshold is selected to remove system and background noise. The AE are quantified as RDC over a pre-defined monitoring period, which is typically 15 to $30 \mathrm{~min}$ in length; hence, the system provides 'near' real-time information on the slope status (i.e. at the end of each monitoring period of 15 to $30 \mathrm{~min}$, an alert can be triggered if the threshold is exceeded). Extensive research including multiple field trials (e.g. Berg et al. 2018; Dixon et al. 2015a; Dixon et al. 2015b; Smith and Dixon 2015; Smith et al. 2014; Smith et al. 2017a) has demonstrated that $\mathrm{AE}$ rates are indicative of slope displacement rates, and hence, this instrumentation is defined as a slope displacement rate sensor. Activity status of the slope (e.g. stable, accelerating and decelerating deformation trends) is obtained, and critical thresholds for $\mathrm{AE}$ rates based on derived deformation rates (i.e. velocities) and the landslide velocity scale (e.g. Hungr et al. 2014) can be set and exceedance of these communicated to nominated persons (i.e. an alert message). 
Benefits of the Slope ALARMS system include continuous operation, high sensitivity able to detect very slow displacement rates, remote, automatous and robust operation, production of (near) real-time warnings and lower costs than current subsurface in-place deformation instrumentation for continuous measurements (e.g. in-place inclinometers and ShapeAccelArrays). However, despite providing a lower cost solution, the Slope ALARMS system is still too costly and complex for use as part of a community EWS in low- and middle-income countries. This has motivated development and testing of a simpler and lower cost AE-based alarm slope monitoring system, which is described here as Community Slope SAFE (CSS). The device has been optimised to meet the needs of its target user base (i.e. the community), which are not geotechnical experts, and therefore, the design is not constrained by the requirements of a warning system for use by landslide professionals.

\section{Community Slope SAFE approach}

A key motivation for developing the CSS approach is not only to establish performance of a continuous (near) real-time subsurface slope monitoring system that can be manufactured at the lowest possible cost but also to deliver a system that can be looked after by a community. It is important that nonspecialists can install and set up the system and for community members to maintain and use the EWS. It is envisaged that technical support for installation, setup and troubleshooting would be provided by a small team located in a region (e.g. working for an NGO or government agency) that would be trained to provide this technical support. The expectation is that humanitarian and/or government funding sources could provide hundreds of CSS systems in a region prone to landsliding. Communities would need guidance from country-based hazard assessment specialists to select the slopes that pose the highest risk, and hence advise on where best to locate sensors. The technical support team would then direct the community to install and operate the monitoring system. The community would also be guided to develop emergency response plans in case of an alert being triggered (e.g. Emergency Management Australia 2001). A key element of this EWS concept is that the community will be custodians of the monitoring system so that they actively protect and maintain the installation. There are examples of where this type of partnership has led to successful installation and community operation of hazard EWS in lowand middle-income countries such as flood monitoring in India (United Nations Framework Convention on Climate Change 2017).

Using experience gained developing and operating the Slope ALARMS system and also taking advantage of the rapid recent advances in electronics, the sensor design, method of installation and system operation framework have all been reviewed and revised to deliver a simpler and lower cost EWS that is optimised for use by a community. Figure 2a shows a schematic of the system installed in a slope; Fig. $2 b$ details the main components and operating architecture for the approach; Fig. $2 \mathrm{c}$ shows photographs of the sensor and base station components of the CSS system, and Fig. $2 \mathrm{~d}$ shows the method of sensor connection on the waveguide.

Key innovations in the Community Slope SAFE system and differences to Slope ALARMS are
- Quantification of the AE signal voltages using root mean square (RMS) to produce a measure of $\mathrm{AE}$ energy per unit time, which replaces use of RDC rates in Slope ALARMS.

- Simplified setup, operation and communication protocols.

- A base station module designed to communicate with the sensors for setup, health checks, log performance parameters and receive alert messages, which are then actioned by triggering a siren and flashing light.

- Installing steel waveguides by driving them into the ground rather than using the more costly procedure of placing the steel waveguide in a pre-drilled borehole.

As shown in Fig. 2b, the CSS system comprises the following functions: conversion of $\mathrm{AE}$ (i.e. stress waves) propagating along the steel waveguide to voltages using a piezoelectric transducer; amplification of the signal and filtering to remove noise at both low $(<15 \mathrm{kHz})$ and high $(>40 \mathrm{kHz})$ frequencies that can be generated by the electronics and/or environmental factors; calculation of the signal RMS (i.e. a measure of signal energy); aggregating the RMS values over a defined time period (e.g. $30 \mathrm{~s}$ ) to calculate the average AE activity over this monitoring period; comparison of the AE RMS rate over the aggregation period with a pre-determined threshold value; and generation of an alert message to the community via the base station if the threshold is exceeded, which sets off an audible and visual alert. This alerts the community to activate a preagreed action plan such as evacuation of a specified area using agreed routes, inspecting the slope if safe to do so and informing nominated authorities and professionals. The system has been designed for low-cost manufacture and low-power usage. It has been estimated from the bill of materials that a single sensor would, at current prices, cost in the region of a few hundred dollars (US) to manufacture, and this cost would reduce for manufacture in large numbers (note that the sensor is one element of the system).

Using driven steel tube waveguides simplifies the installation process by using readily available low-cost equipment (e.g. hand-operated post rammers), and this also reduces costs; although the depths that they can be driven to will depend on the strength and stiffness properties of the host soil. As an example, waveguides were driven to depths exceeding $10 \mathrm{~m}$ in a recent field trial in Malaysia. Installation of a waveguide by driving results in the tube being in intimate contact with the in situ ground forming the slope. It is possible for the host soil to be granular (e.g. some decomposed granites which are typically found in South East Asia), which will generate detectable levels of $\mathrm{AE}$, but it is also likely that in many applications, the soil forming the slope will be predominantly 'quiet' fine-grained soil. This limitation is overcome by placing noisy material inside the waveguide (e.g. Nakajima et al. 1991) such that as the tube is deformed by slope movements, deformations of the infill generate AE that propagate to the surface via the steel tube where they can be detected and quantified by the sensor. Sand is an ideal material to use as the noisy infill material as it is cheap and universally available, but waste products such as crushed glass can also be used.

The following sections describe and present results from a programme of laboratory testing designed to assess performance 

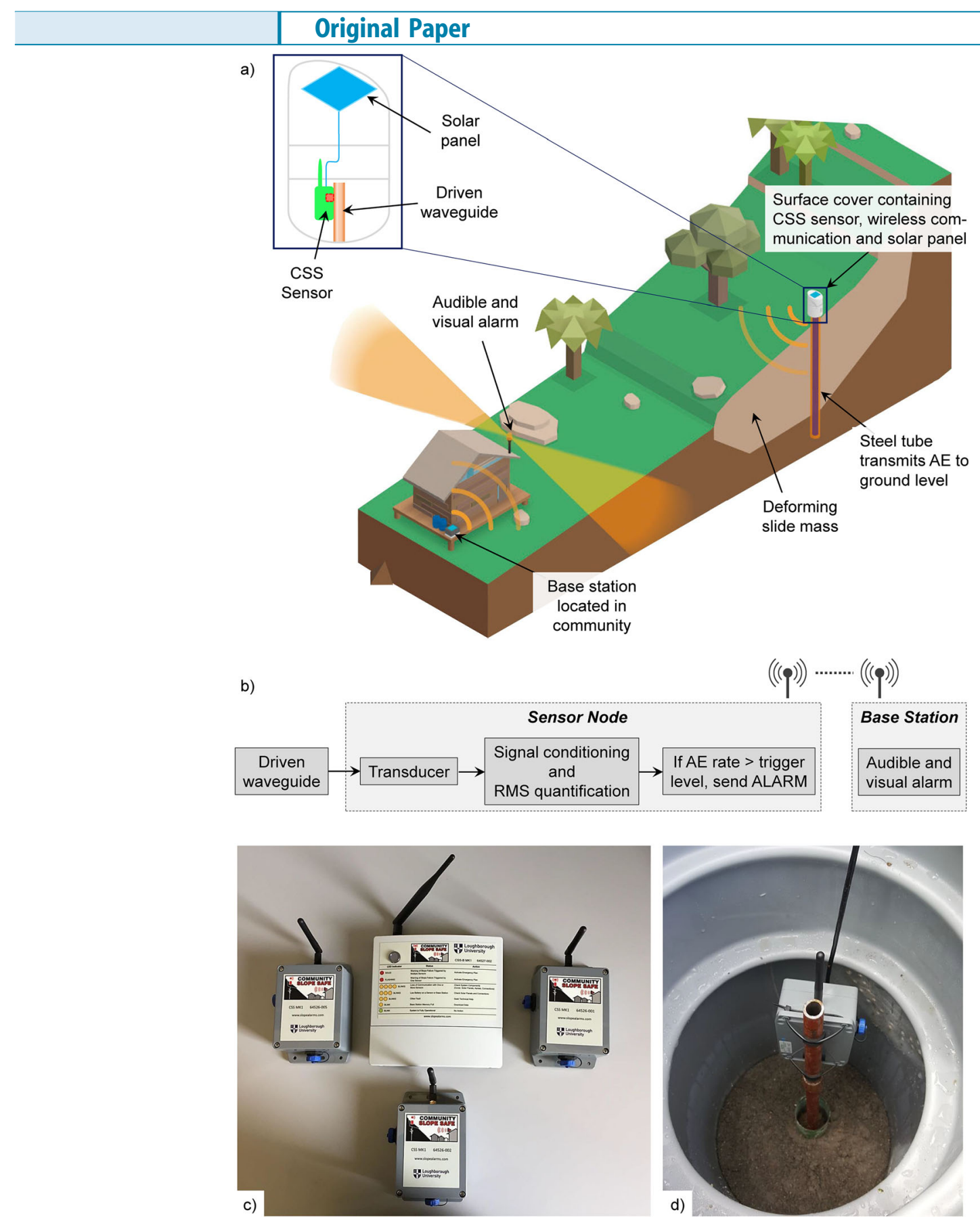

Fig. 2 a Community Slope SAFE AE monitoring approach incorporating a driven waveguide. b System architecture of the Community Slope SAFE approach. c CSS sensor and base station components. $\mathbf{d}$ A view of a sensor located on the waveguide inside a cover

of the CSS approach, including the use of driven waveguides with noisy infill.

\section{CSS performance evaluation using physical model experiments}

\section{Introduction}

Series of physical model experiments were conducted to evaluate performance of the CSS AE monitoring approach by comparing applied deformation behaviour of waveguides with the measured AE response. Accelerating landslide events have been simulated in two ways: (i) a large scale simulated first-time landslide failure experiment using a waveguide with external fill to compare performance of CSS directly with the published performance of the Slope ALARMS system (Smith et al. 2017a) and (ii) series of experiments conducted using displacement-controlled bending tests on active waveguides with internal fill to understand repeatability and establish relationships between AE and displacement rates for different tube diameters and infill types. In all tests, the waveguides were subjected to accelerating deformations to replicate known behaviour in first-time landslides, which accelerate as 


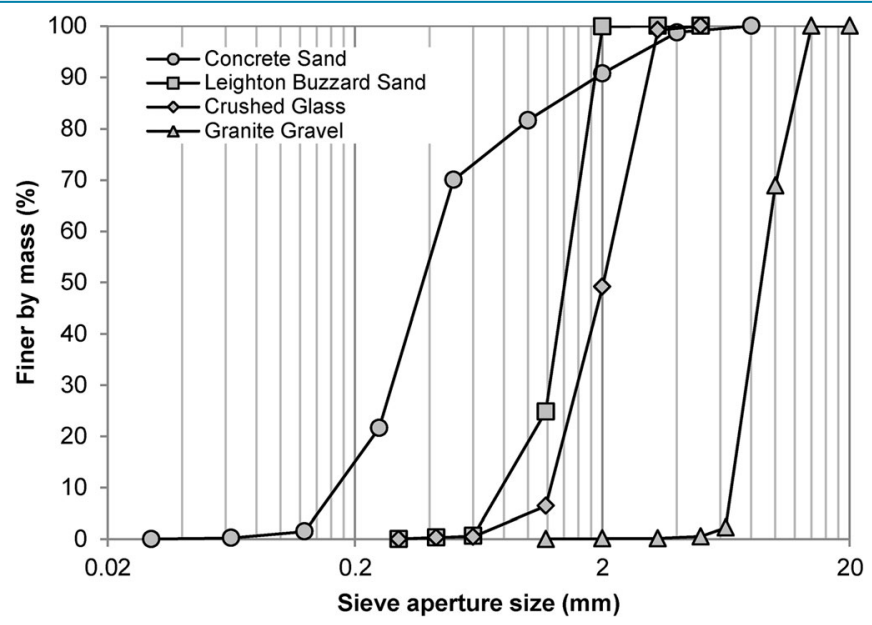

Fig. 3 Particle size distributions of the soils used in the physical model experiments

progressive failure occurs and post peak strengths are mobilised (e.g. Leroueil 2001; Cooper et al. 1998).

The noisy fill materials used were angular fine to medium GRAVEL (crushed granite) for the external fill in experiment (i) and subangular uniformly graded coarse SAND (Leighton Buzzard sand), subrounded well-graded fine to coarse SAND (described here as concrete sand) and subangular uniformly graded 1 to $3^{-}$ $\mathrm{mm}$-sized crushed GLASS as infill used in experiment series (ii). The gradings for the four materials are presented in Fig. 3. Two versions of the CSS sensor were used in the laboratory investigation: Initially, the first pre-prototype hand fabricated sensor with external transducer, denoted CSS HPP, was used in (i) and the first

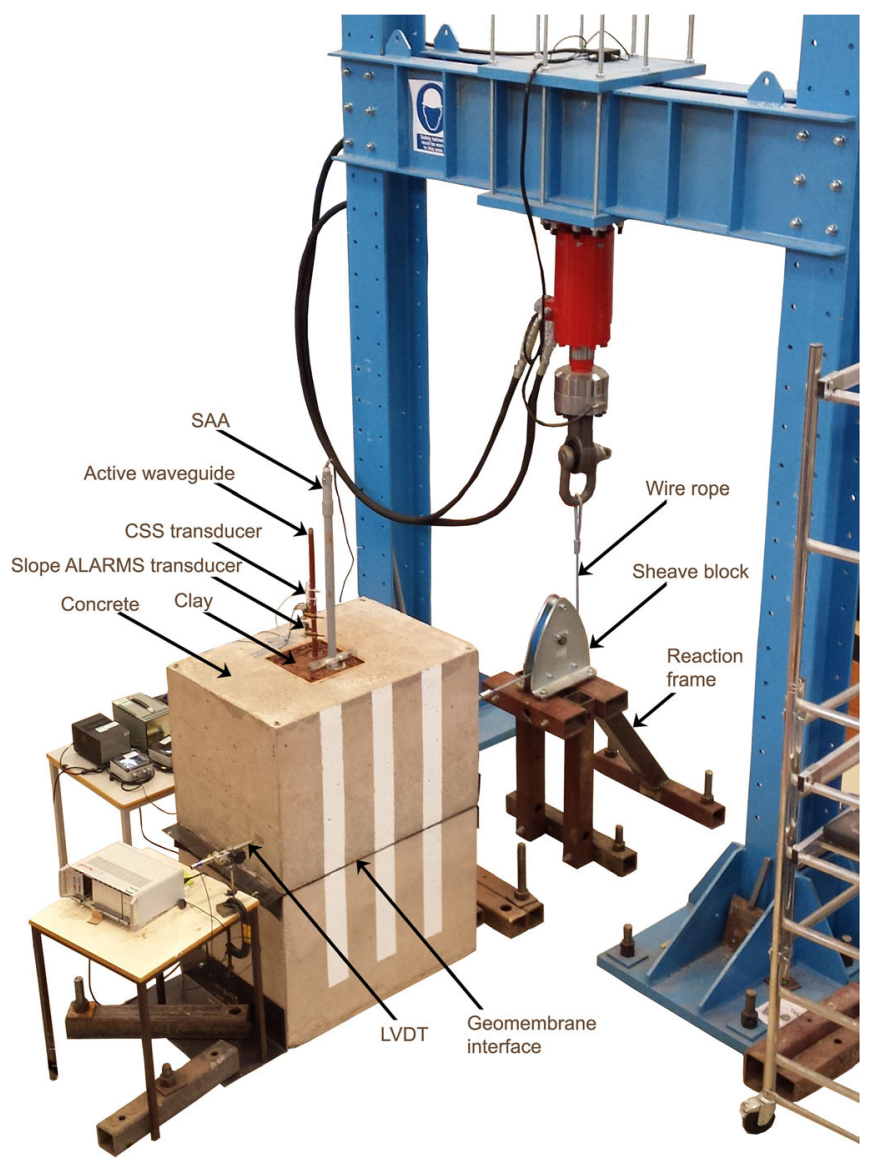

Fig. 4 Annotated photograph of the large-scale slope failure physical model used to accelerate the top box relative to the bottom and to compare displacement behaviour with AE measured using both the Slope ALARMS and CSS HPP sensors (after Smith et al. 2017a) 
series of tests in (ii), and subsequently, a re-designed for mass manufacture factory production prototype sensor, denoted CSS MP, was used for a second series of tests in (ii). These two CSS sensors have comparable component architectures and operating systems, but evolution of the electronics and components means that the magnitudes of $\mathrm{AE}$ produced by the two devices are not directly comparable, although $\mathrm{AE}$ trends are analogous. All waveguide tubes used were steel with $3-\mathrm{mm}$ wall thickness manufactured to EN10255 (2004) and EN10217-1 (2005), which are produced for use as gas distribution pipes. These types of pipes with a range of geometries have been employed in all previous field installations of the Slope ALARMS system for both technical and practical reasons (Dixon et al. 2015a). The wall thickness of the tube is selected to optimise the propagation of $\mathrm{AE}$ long distances with minimum attenuation, hence enabling $\mathrm{AE}$ generated at depth within a slope to be transmitted to the sensor at ground level (Smith et al. 2017b). In addition, the 3-mm tube thickness facilitates threading of the tube to allow use of screw couplings between lengths, which aids rapid installation and also minimises attenuation of AE at the connections (Smith et al. 2017b).

\section{Performance of CSS sensor}

The first stage in assessing performance of the CSS monitoring concept was to undertake a simulated first-time failure experiment

(a)

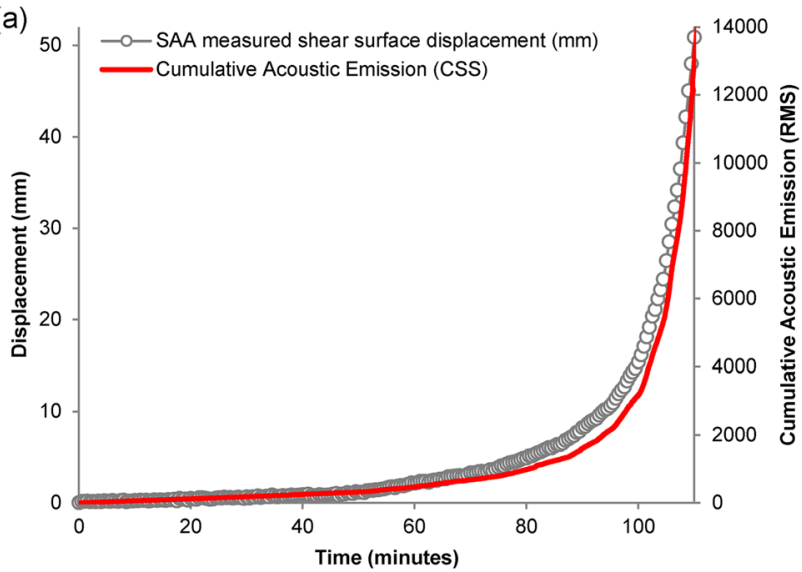

(b)

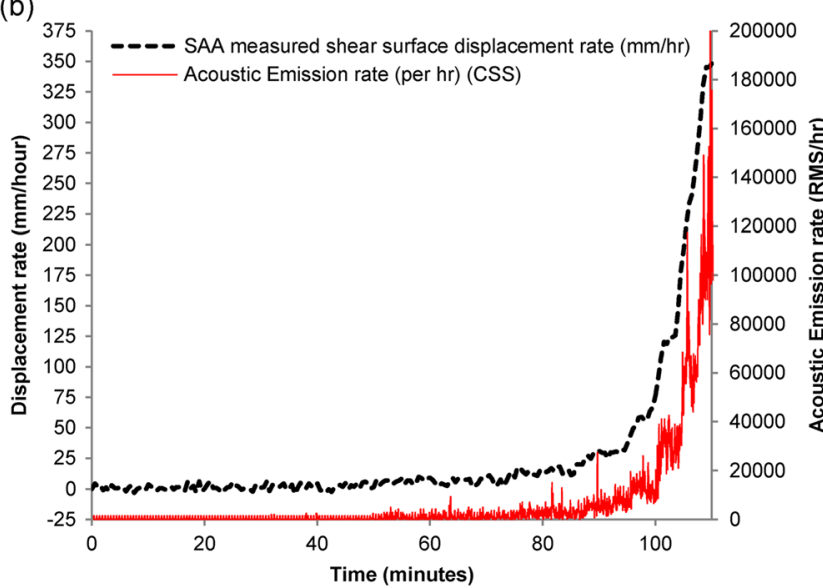

with simultaneous monitoring of displacements and $\mathrm{AE}$, the latter using both Slope ALARMS and CSS HPP sensors. A waveguide with external backfill (i.e. active waveguide) was installed in a large-scale direct shear device in which a shear surface was formed in a column of stiff clay surrounding the waveguide and the sliding mass accelerated reaching displacement rates greater than $300 \mathrm{~mm} / \mathrm{h}$ and shear deformations of $50 \mathrm{~mm}$. Figure 4 shows the experimental setup, and full details of the test procedure are reported in Smith et al. (2017a). The granular waveguide backfill was the granite gravel described in Fig. 3. The waveguide was formed by creating a borehole $60-\mathrm{mm}$ diameter through the column of clay, which represents in situ soil of a slope. A plastic access tube was grouted into a second 60-mmdiameter hole through the clay to house a ShapeAccelArray (SAA) in-place inclinometer with gauge length $200 \mathrm{~mm}$. Displacement of the top concrete block relative to the bottom block was by a pulley system controlled by a hydraulic actuator. The experiment was designed to undertake a series of repeat tests to assess performance of the Slope ALARMS sensor during accelerating displacements, but availability of the CSS HPP for the last test of the series gave an opportunity to measure AE generated by deformation of the waveguide system using both the Slope ALARMS and CSS HPP sensors.

Figure 5 a, c shows cumulative AE measured using Slope ALARMS and CSS HPP sensors and displacements measured by the SAA, all plotted against time for the duration of the accelerating shear
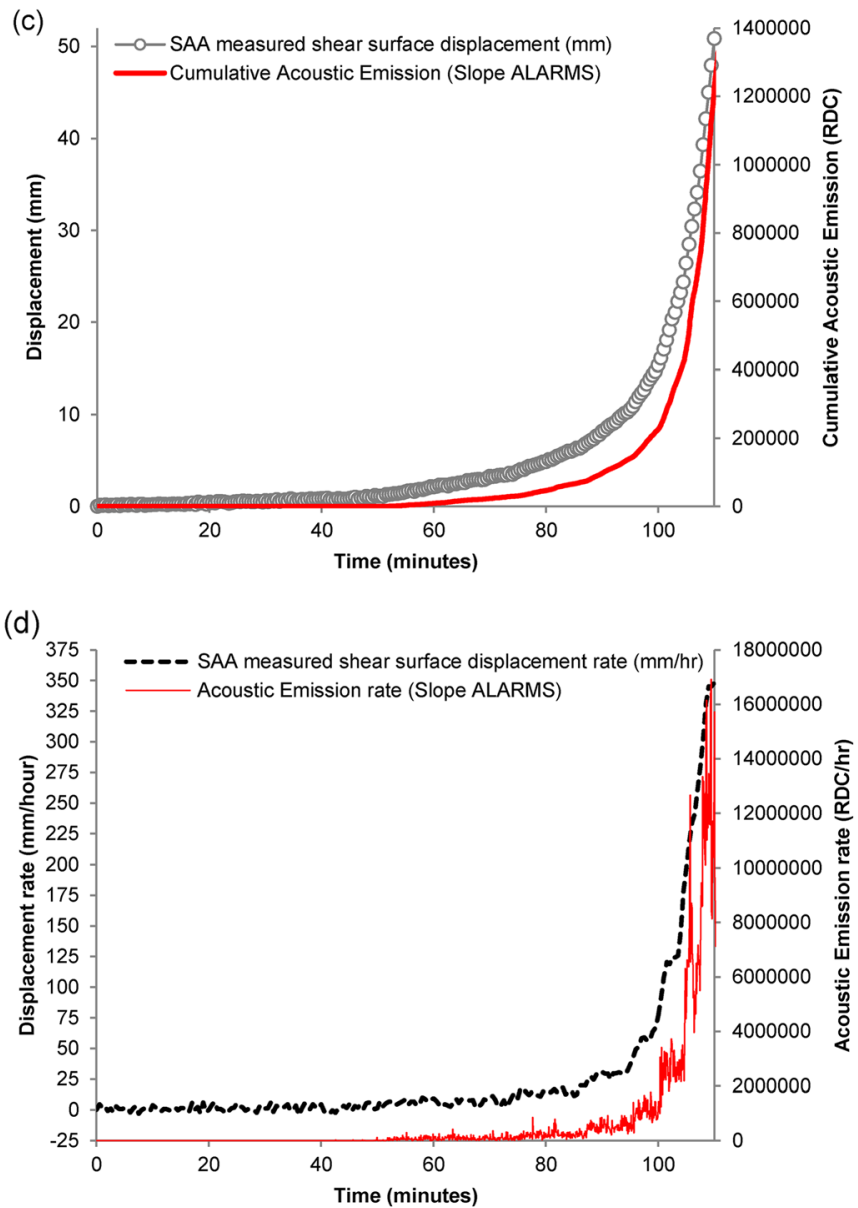

Fig. 5 Results from the large-scale slope failure simulation. a CSS cumulative AE and SAA measured displacement time series. b CSS AE rate and SAA measured velocity time series. $\mathbf{c}$ Slope ALARMS cumulative AE and SAA measured displacement time series. $\mathbf{d}$ Slope ALARMS AE rate and SAA measured velocity time series 


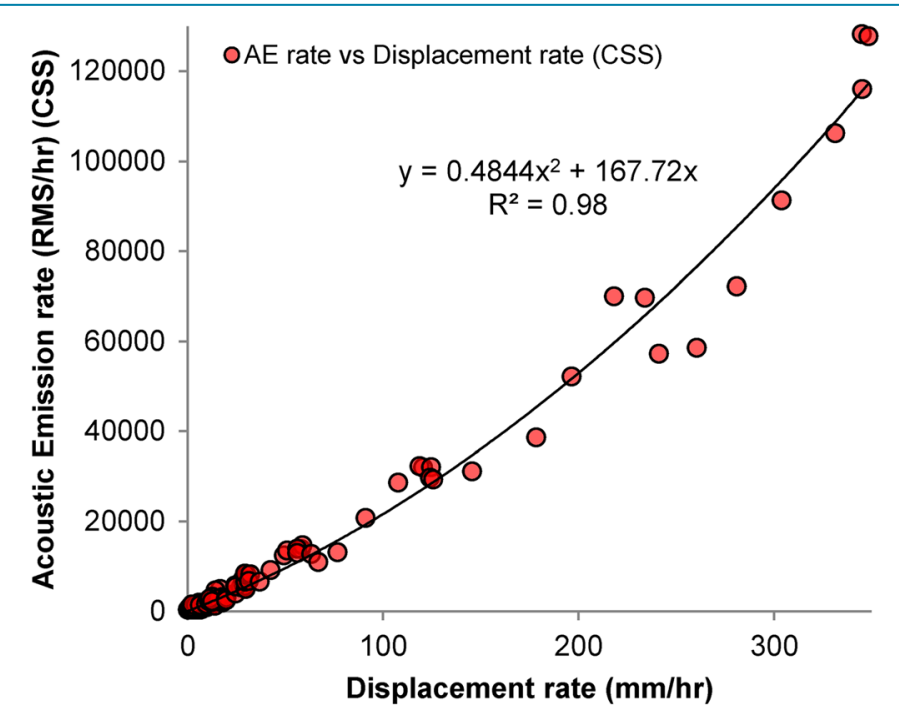

Fig. 6 Relationship between CSS HPP AE rates (per hr) vs. SAA displacement rates (plotted using 2-min moving averages)

movements. All measured parameters (i.e. AE RDC and RMS values and displacements) describe the same exponentially increasing trend. This is also shown by the $\mathrm{AE}$ and displacement rate trends with time (Fig. 5b, d). Figure 6 presents the correlation between AE rates measured using the CSS HPP sensor and displacement rates measured using the SAA. A polynomial relationship can be defined with strong correlation and which is comparable to the results presented in Smith et al. (2017a) for the Slope ALARMS system. The excellent agreement between $\mathrm{AE}$ and displacement trends (i.e. cumulative and rate) provides conclusive evidence that $\mathrm{AE}$ rates are indicative of 'slope' displacement rates, and hence that $\mathrm{AE}$ monitoring can be used to provide information on the stability status of a slope. This experiment has shown that the CSS HPP sensor can measure AE trends that are comparable to those obtained using the Slope ALARMS sensor.

\section{Infill waveguide system: proof of concept}

As use of waveguide infill soil is untried, a programme of testing has been conducted to ascertain whether infilled waveguides monitored using CSS sensors also generate AE that are indicative of displacement trends. Experiments have been conducted to deform 450-mm lengths of waveguide comprising steel tube with soil infill. Three point bending tests were carried out using an Instron test machine with computer control to deform the waveguide through increasing rates of displacement (Fig. 7). The infill was placed in approximately $100-\mathrm{mm}$ lifts with each layer compacted using impacts from a steel rod. The single-sized soils do not achieve a dense state, and therefore, this installation procedure was focussed on ensuring that large air voids did not form through bridging, rather than trying to achieve a specific enhanced density of the infill.

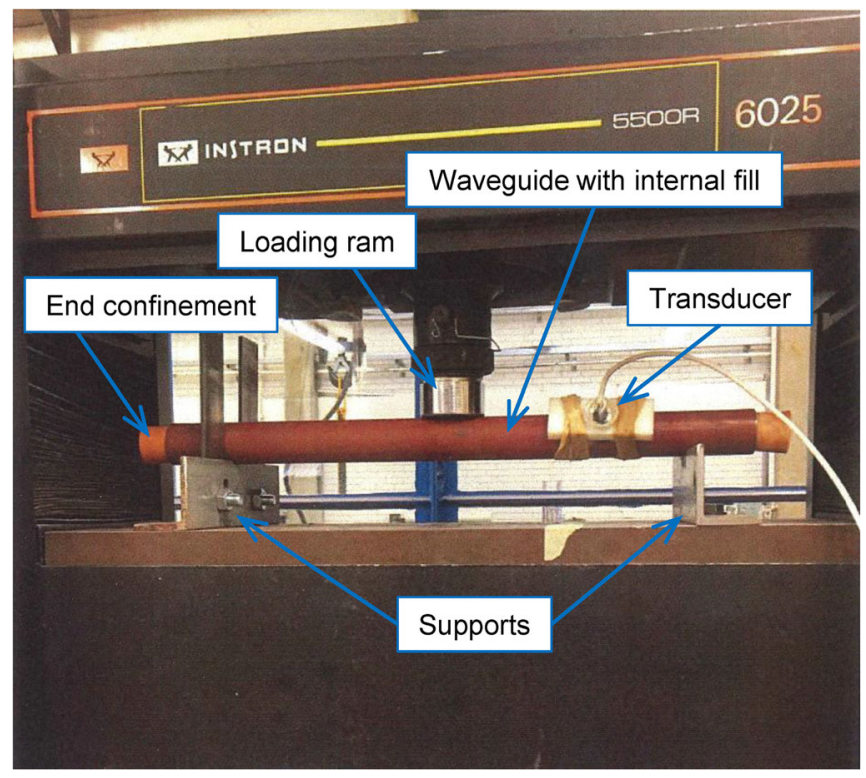

Fig. 7 Three point bending experimental set up for a steel waveguide with infill. The transducer from the CSS HPP system is attached to the tube on the right hand side 
Four groups of tests were conducted to investigate repeatability, waveguide tube diameter and infill type.

An initial series of repeat tests was conducted using $42-\mathrm{mm}$ diameter tube with Leighton Buzzard sand infill for deformation rates increased in three steps from $0.5 \mathrm{~mm} / \mathrm{min}$ for $5 \mathrm{~mm}$ through $2 \mathrm{~mm} / \mathrm{min}$ for $5 \mathrm{~mm}$ to $6 \mathrm{~mm} / \mathrm{min}$ for $12 \mathrm{~mm}$. Figure 8 a presents the $\mathrm{AE}$ as a rate per minute (i.e. an equivalent value calculated using the measured value multiplied by 12) for each 5-s monitoring period during the test; Figure $8 \mathrm{~b}$ shows cumulative AE with time and $\mathrm{c}$ the correlation between $\mathrm{AE}$ and displacement rates for the end of each increment.

The AE vs. displacement trends shown in Fig. 8 provide clear evidence that $\mathrm{AE}$ rates generated by deformation of a steel tube with sand infill are indicative of the displacement rates of tube deformation. AE are generated by particle-to-particle and particleto-steel dislocations resulting from the differential strain both across the diameter and along the length of the tube as it bends. However, the measurements indicate that there are threshold magnitudes of displacements below which detectable AE are not generated. This threshold value is $5-\mathrm{mm}$ cumulative displacement for the tests shown in Fig. 8, but it varies as demonstrated by subsequent tests presented below. This behaviour is because sufficiently large differential strains are required across the steel tube to cause the particle dislocations that can generate detectable AE. It is also important to note that following a change in waveguide displacement rate, the $\mathrm{AE}$ rate increases until it reaches a constant value (i.e. shown by the $\mathrm{AE}$ rate curves becoming horizontal in Fig. $8 \mathrm{a})$. Therefore, $\mathrm{AE}$ rate vs. displacement rate relationships are only
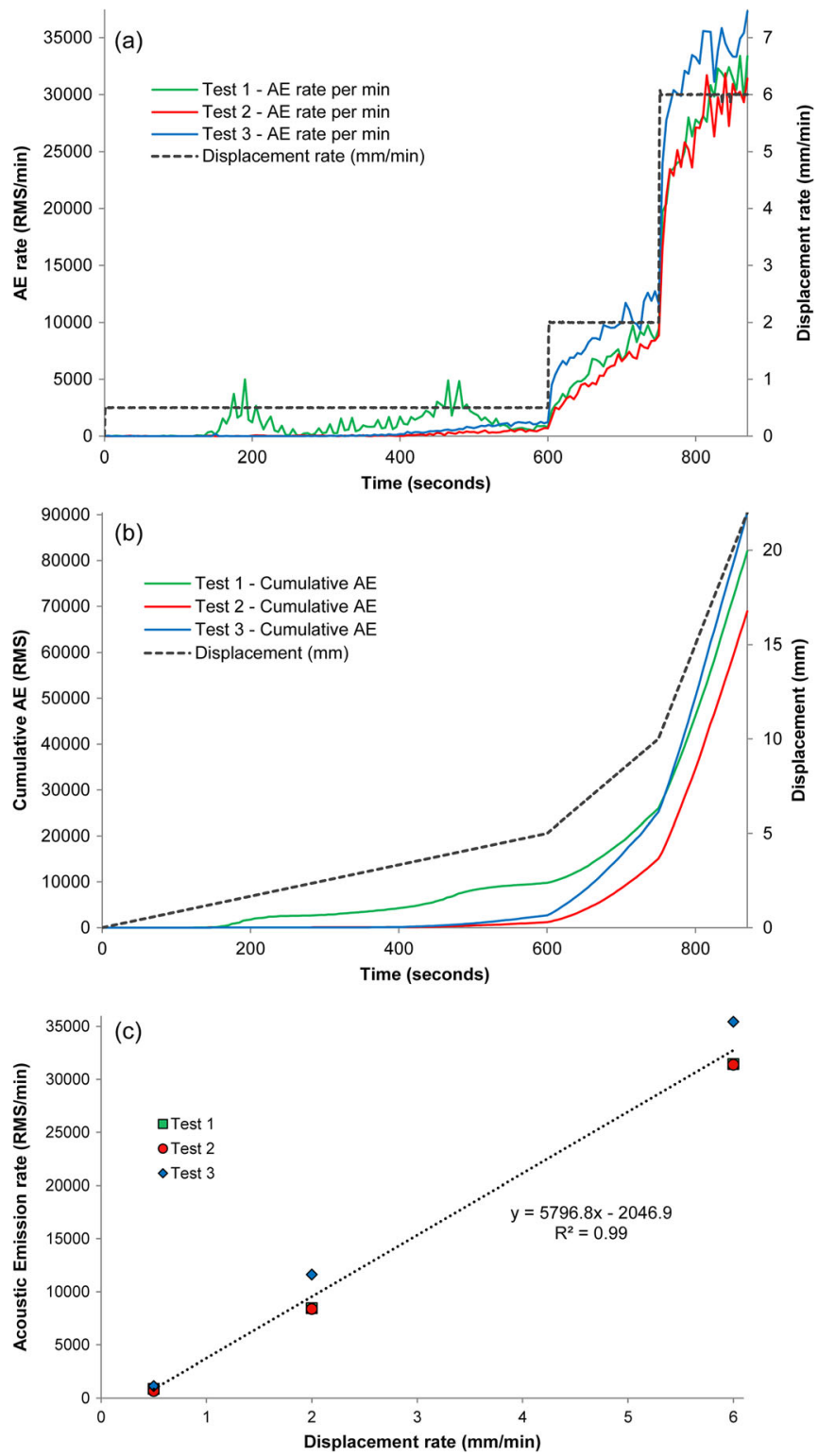

Fig. 8 Results for stepped accelerating deformation of a 42-mm internal diameter steel waveguide with Leighton Buzzard sand infill material and AE measured using a CSS HPP sensor. a AE rate and displacement rate time series. $\mathbf{b}$ Cumulative AE and displacement time series. $\mathbf{c}$ Regression between AE and displacement rates for the end of each increment 
constant once the displacement rate has been established, which might take several $\mathrm{mm}$ of displacement at a specific rate.

\section{Influence of waveguide diameter}

Successful operation of the hand-built pre-prototype CSS sensor (CSS HPP) used with infilled waveguides described in the former test series led to a decision to develop the sensor further by redesigning it for low-cost high-volume manufacture: the CSS MP sensor. The CSS MP sensor was used for all tests reported below. A key parameter in design of $\mathrm{AE}$ waveguides is the diameter of the steel tube. There are two conflicting requirements: minimise the tube diameter to aid installation of the waveguide to the required depth, which may be several metres, using easily available hand held equipment, and maximise the diameter to increase the crosssectional area of infill that can interact to generate AE during bending. Figure 9 shows cumulative AE vs. time graphs for tests conducted using the same setup shown in Fig. 7, with one test each on steel tubes with internal diameters 15,27 , and $42 \mathrm{~mm}$, all with Leighton Buzzard sand infill. The tubes were all deformed using a displacement vs. time relationship that accelerates the displacements from 0.1 to $6 \mathrm{~mm} / \mathrm{min}$ in 10 2-min increments, shown as straight segments in the displacement relationship in Fig. 9. Note that the vertical scale for the RMS values plotted increases with increasing diameter. All AE trends show an increasing rate with displacement rate; however, the magnitude of generated $\mathrm{AE}$ is significantly different. The $15-\mathrm{mm}$-diameter waveguide generates total $\mathrm{AE} 8 \%$ of the $\mathrm{AE}$ for the $27-\mathrm{mm}$ diameter, which in turn is $7 \%$ of the total AE for the 42-mm-diameter waveguide. This demonstrates the value of using the maximum diameter of steel tube that can be driven into the ground at a given site. In addition to the increased $\mathrm{AE}$ rates generated as the diameter increases (i.e. increased volume of infill soil), it can also be seen in Fig. 9 that sensitivity of the system is improved as the waveguide diameter increases, with smaller displacement rates detected using $\mathrm{AE}$ earlier in the test as the diameter increases.

\section{Influence of waveguide infill type}

To investigate whether the AE/displacement rate trends obtained using Leighton Buzzard sand infill are produced by other granular infill materials, tests were conducted using the $27-\mathrm{mm}$ internal diameter tube with Leighton Buzzard, crushed glass and concrete sand infills. The gradings of the infill materials are shown in Fig. 3, and the test procedure and displacement rates are the same as described above. Figure 10 presents the cumulative AE RMS values obtained for the three infills where they are compared to the tube displacement trend. Although this study is limited to three infill materials, comparable $\mathrm{AE}$ and displacement trends are obtained, with both showing increasing rates (i.e. increasing slopes of the curves). These results clearly demonstrate that a range of granular infill materials can be used to produce an active waveguide that generates $\mathrm{AE}$ rates indicative of the rate of tube displacement. This is an important finding because it means that local materials can
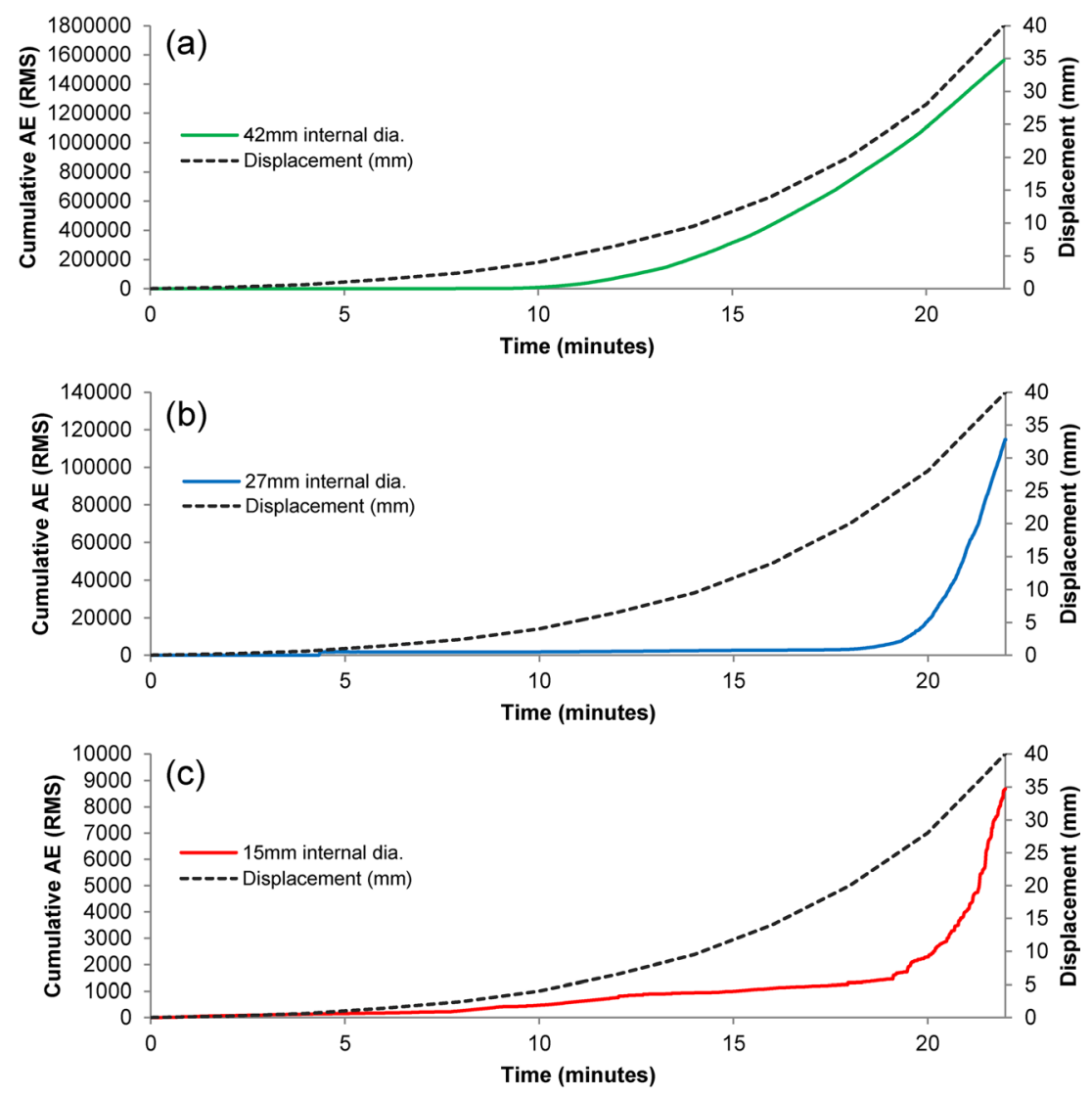

Fig. 9 Comparison of AE generated by displacement of a $42 \mathrm{~mm}, \mathbf{b} 27 \mathrm{~mm}$, and c $15 \mathrm{~mm}$ internal diameter tubes with sand infill and using CSS MP (note the different $y$ axis scales) 


\section{Original Paper}
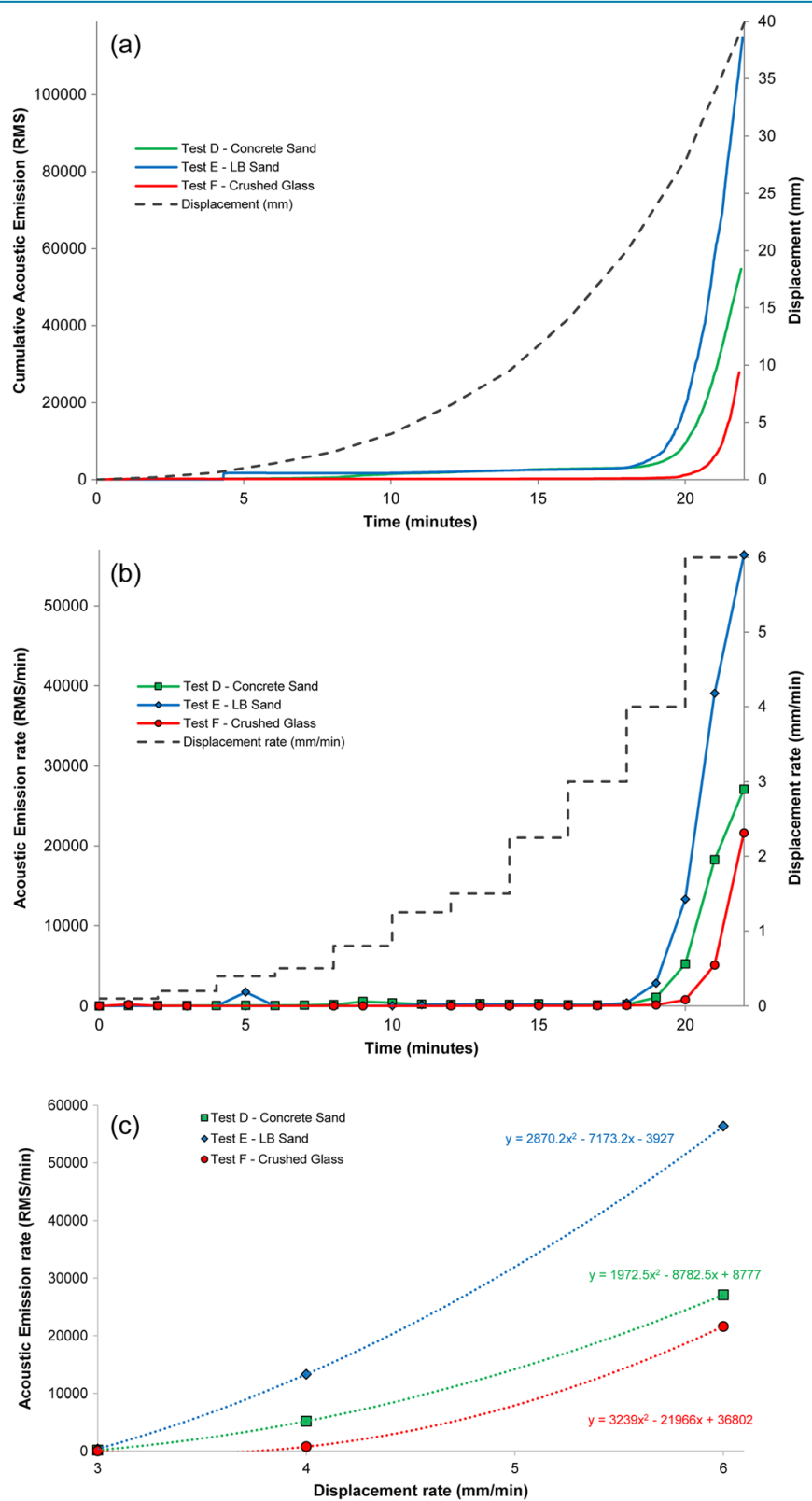

Fig. 10 Comparison of AE generated by Leighton Buzzard sand, concrete sand, and crushed glass infills by displacement of a 27-mm internal diameter tube and using sensor CSS MP. a Cumulative, $\mathbf{b}$ rate, and c AE rate-displacement rate relationships between 3 and $6 \mathrm{~mm} / \mathrm{min}$

be used to construct waveguides for slope monitoring, which simplifies the construction logistics and reduces costs. However, it should be noted that the relationship between AE and displacement rates is infill dependent (Fig. 10c) and must be taken into consideration when defining threshold levels used to trigger an alarm, as discussed in the next section.

\section{Repeatability and $A E /$ displacement rate relationships}

Tests were conducted to replicate those described in the "Infill waveguide system: proof of concept" section but using the CSS MP sensor and the accelerating displacement profile shown in Fig. 10. All tests used the 15-mm internal diameter tube, Leighton Buzzard sand infill and the test method shown in Fig. 7. Figure 11 shows cumulative $\mathrm{AE}$ (a) and $\mathrm{AE}$ rate (b) relationships with time for three repeat tests and (c) regression between $\mathrm{AE}$ and displacement rates for the end of each increment between 3 and $6 \mathrm{~mm} / \mathrm{min}$. Also shown is the tube displacement vs. time relationship. All three tests show comparable behaviour, with rapidly increasing rates of generated $\mathrm{AE}$ for displacement rates $>4 \mathrm{~mm} / \mathrm{min}$. This demonstrates consistent and repeatability of behaviour and allows the identification of threshold levels for AE rates that are indicative of significant accelerating slope movements, and hence, they could be used to trigger an alert message. The transition from relatively low to rapidly increasing $\mathrm{AE}$ rates occurs after a displacement magnitude threshold is reached, mobilising significant AE generation in the infill, and this results in polynomial relationships 

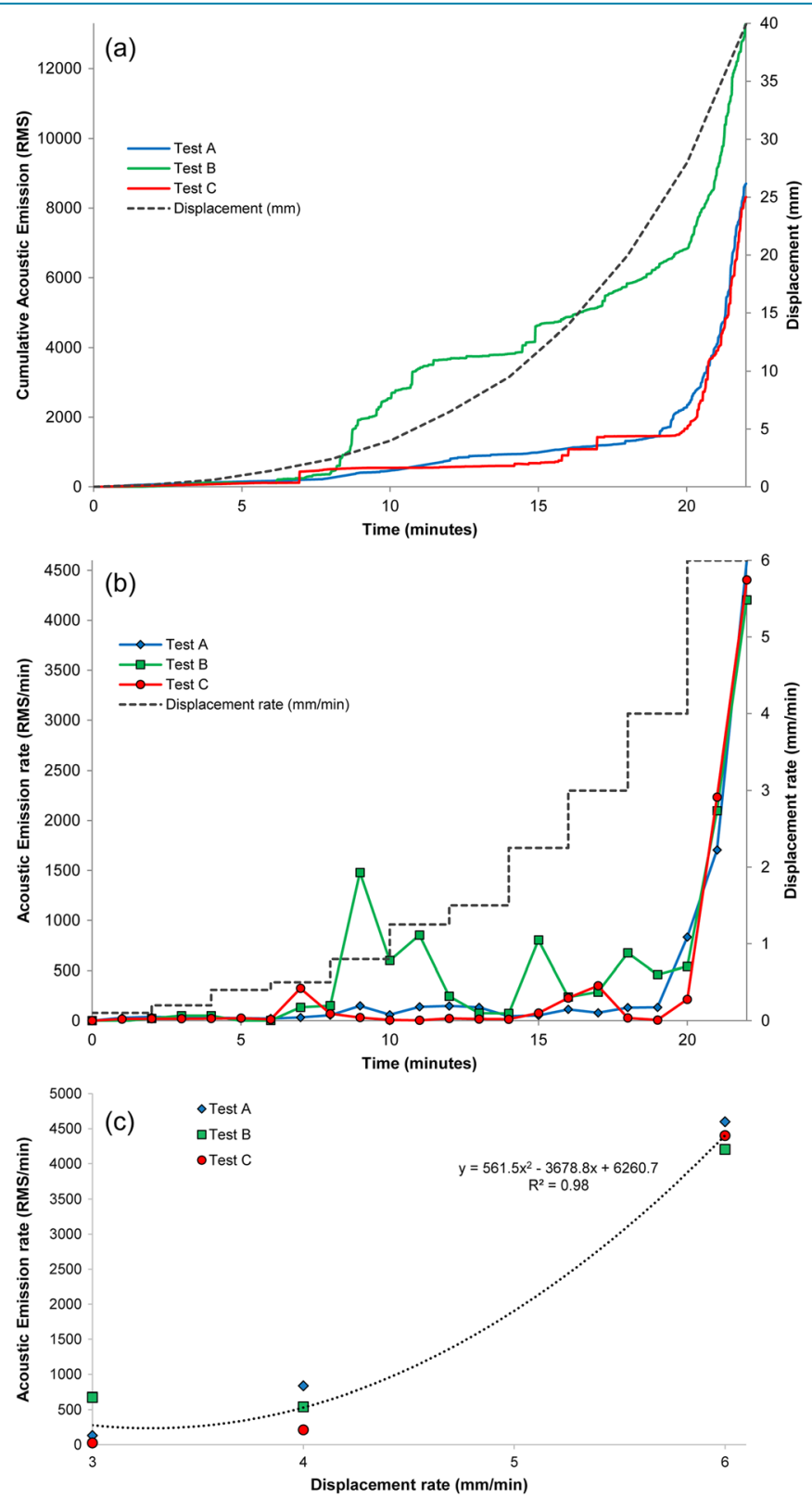

Fig. 11 Comparison of a cumulative AE RMS and b AE RMS rates per minute for repeat tests using the 15-mm internal diameter tube, Leighton Buzzard sand infill, and sensor CSS MP, and c regression between AE and displacement rates for the end of each increment between 3 and $6 \mathrm{~mm} / \mathrm{min}$

achieving the greatest statistical match to the measured relationships over the range of values examined (consistent with the findings in Smith et al. 2017a).

Although test B shows this accelerating AE trend, there was untypical relatively high $\mathrm{AE}$ detected at displacement rates between 0.5 and $2 \mathrm{~mm} / \mathrm{min}$. However, this AE at lower displacement rates is not thought to be generated by deformation of the tube/infill assembly. This conclusion is reached because the load vs. deformation relationship for this test is the same as all the other tests presented in Fig. 11, and hence, there is no additional input of energy into the system that could have caused increased interaction between the infill and tube. Therefore, it is likely to be due to spurious background noise in the test area.
Some instances of loud noise generated by contact between metallic objects (i.e. with a high frequency component) occurred during testing as recorded by the operator. This type of noise is not expected to occur in field applications, where environmental sources such as weather generated (e.g. wind and rain) and activities of people, generally generate lower frequency noise and this will be filtered out by the sensor (i.e. frequencies $<15 \mathrm{kHz}$ are removed) (Koerner et al. 1981). However, this example of contamination of the measured AE trend demonstrates the importance of providing a robust cover for the waveguide/sensor field assembly to minimise the impact of any environmental noise, and it also has implications when selecting threshold trigger levels as discussed below. 


\section{Selecting an AE threshold}

The central aspect of the CSS EWS is the use of a single threshold associated with a target slope displacement rate to trigger action by the community. To define a threshold based on AE RMS rate and generate an alert of impending slope failure requires knowledge of waveguide configuration (i.e. diameter and infill), sensor settings such as frequency range and aggregation period over which the $\mathrm{AE}$ rate is calculated (e.g. 30, 60, 180 s) and slope characteristics including material type, failure mechanism, triggering mechanism and anticipated rate of slope deterioration. Of these factors, waveguide design and sensor settings can be defined; however, it is clear from the above criteria that unless site-specific knowledge is obtained on the slope characteristics, then any threshold that is set is likely to be speculative and of limited use to the community. This statement is valid for the use of any type of slope monitoring instrumentation (e.g. in-place inclinometers and extensometers) because understanding the rate at which a slope will become unstable, leading to rapid displacement rates and large deformations, is needed to set a threshold that will provide an alert in sufficient time to enable the agreed response of the community to be completed (i.e. evacuation to a safe area). This reinforces the need for a community EWS to incorporate local site-specific knowledge to locate the instruments and set appropriate thresholds (UNEP 2012).

A useful framework to help select threshold slope displacement rates is provided by Petley et al. (2005), which links development of a progressive first-time failure within a slope with the existence of linear trends when the reciprocal of velocity prior to failure is plotted against time (Saito 1980). Although there is still a dearth of data for displacement rate (i.e. velocity) time relationships in firsttime failures, sufficient information is available to establish the validity of this linear relationship for a range of circular and translational first-time failures in fine-grained soils and hence the expectation of accelerating displacements during the initiation of the slope failure. Therefore, the task becomes one of identifying a slope displacement rate that can be interpreted as probably leading to a rapid acceleration and failure, and hence, the occurrence of uncontrolled large scale and rapid movement of debris that poses a risk to the community. Using the standard classification scale of slope velocity proposed by Cruden and Varnes (1996), disruptive first-time failures can be classified as Rapid or greater (i.e. Very Rapid through to Extremely Rapid) with the Rapid category defined as slope displacement rates of 30 to $3000 \mathrm{~mm} /$ min. It is proposed that setting a threshold in the Moderate slope displacement range, which is defined as 0.3 to $30 \mathrm{~mm} / \mathrm{min}$, would provide evidence that significant accelerating displacements are occurring and at a level that indicates a first-time failure event is possible. For a given waveguide design (i.e. diameter and infill) and sensor settings, this approach can be implemented by selecting an AE RMS rate that is indicative of slope displacement rates in the order of 5 to $10 \mathrm{~mm} / \mathrm{min}$ (i.e. in the middle of the Moderate range). This can then be used as the threshold such that exceedance of this $\mathrm{AE}$ rate triggers an alert message. However, a decision is also required on the length of time over which this rate of displacement is recorded before an alert is triggered. It is proposed that this monitoring period (i.e. the aggregation period in the CSS system) should be in the order of 30 to $60 \mathrm{~s}$ as this would indicate sustained slope movements at a Moderate rate.

Figure 11 presents relationships between $\mathrm{AE}$ and displacement rates for the Leighton Buzzard (LB) sand infilled 15-mm internal diameter tube tests $\mathrm{A}$ to $\mathrm{C}$, and these show that when displacement rates are below $4 \mathrm{~mm} / \mathrm{min}$, the $\mathrm{AE}$ rates are typically low (i.e. $<500$ RMS per minute) with limited sensitivity to changes in displacement rate; however, above $4 \mathrm{~mm} / \mathrm{min}$, there is a clear correlation of increasing rates of $\mathrm{AE}$ with displacement. For this specific waveguide configuration, an AE RMS rate in the order of 4400 RMS per minute could be used as a threshold value for $6 \mathrm{~mm} / \mathrm{min}$ displacement rate and hence used to generate an automated landslide alarm. As noted above, the threshold value selected is dependent on a number of factors. Based on the testing conducted in this study, Table 1 summarises the AE RMS thresholds obtained from a range of waveguide configurations and two versions of the CSS sensor.

Experience with active waveguides using external backfills has demonstrated that groups of materials have similar AE behaviour when deformed (e.g. Smith et al. 2017a). Comparable behaviour is shown in Table 1 for the three varied infill materials used with the 27-mm-diameter tube, which have RMS per minute values of the same order. This demonstrates that it would be possible to assign a single value for the threshold AE rate for a group of similar infill materials. The approach described is robust because AE rates for displacement rates around $6 \mathrm{~mm} / \mathrm{min}$ are an order of magnitude greater than those generated for displacement rates below $3 \mathrm{~mm} /$ min. Hence, the approach does not aim to differentiate a difference of a few tens or even hundreds of AE RMS per minute but differences by orders of magnitude (i.e. thousands to tens of thousands). In addition, this eliminates the possibility of triggering a false alert due to spurious background noise such as found in test B shown in Fig. 11. This is important because operating an alarm system automatically for the benefit of the community, and hence without the input of professionals (i.e. as would be the case in a warning system), requires a robust approach that does not generate false alerts, but neither does it miss critical events.

Table 1 Derived AE RMS rate threshold levels for a displacement rate of $6 \mathrm{~mm} / \mathrm{min}$ employing a range of waveguide geometry, infill, and sensors

\begin{tabular}{lllr} 
Sensor & Waveguide diameter $(\mathrm{mm})$ & Waveguide infill & AE RMS rate (RMS/min) threshold for 6 mm/min displacement rate \\
\hline CSS HPP & 42 & LB sand & 32,700 \\
\hline CSS MP & 42 & LB sand & 227,000 \\
\hline CSS MP & 27 & LB sand & 56,000 \\
\hline CSS MP & 15 & LB sand & 4400 \\
\hline CSS MP & 27 & Concrete sand & 27,000 \\
\hline CSS MP & 27 & Crushed glass & 21,600
\end{tabular}


Given the success of the CSS system tests in the laboratory experiments described above, coupled with the development of the interpretation framework, the next step is to conduct field trials in collaboration with community groups. These will be used to develop training materials and test the capability of communities to undertake installation, operation and maintenance tasks; assess performance of the sensor system in field conditions; and evaluate use of the threshold criteria. The first of these trials is in Malaysia in a suburb of Kuala Lumpur. Working with Universiti Sains Malaysia, Slope Branch of JKR, the government public works agency and the community group SlopeWatch, three driven waveguides with sensors were installed in April 2017 on a slope with a history of instability and linked to a base station located in a property at the crest of the slope: Monitoring is ongoing.

\section{Conclusions}

There is without question a need for affordable landslide early warning systems that can be operated by vulnerable communities in low- and middle-income countries. Widespread use of EWS will save lives and help protect critical infrastructure. An existing established framework details the requirements for a community EWS, and this includes the critical components of a sensor-based monitoring and warning/alarm system and a plan for the dissemination of alerts. This paper has for the first time described the development and assessment of a sensor that aims to meet these requirements via measurement of acoustic emission generated by deformation of a waveguide installed in a slope to generate an alert. The Community Slope SAFE approach has been designed to

- Have a low cost so that it is affordable in countries that currently do not instrument slopes, with individual sensors costing in the order of a few hundred dollars (US).

- Be easy to install using simple tools (i.e. hand driven waveguides) and can be maintained and operated by trained community members.

- Operate in a range of different site conditions (i.e. soil types, slope geometries, failure mechanisms and environmental conditions).

- Operate continuously, autonomously and smart (e.g. solar panel system for power recharge, in sensor processing of data and decision making, and wireless telemetry of alert and health messages delivered to the community in a simple format).

- Automatically identify slope deformation rates that could pose a risk to the community.

- Transfer an alert to the user community in real time.

- Be robust with minimal false alerts and with automatic recovery from a sensor failure state (e.g. if power is lost).

A series of laboratory tests that simulate deformation of a waveguide by a first-time slope failure have been used to evaluate performance of the Community Slope SAFE sensor coupled to a simple waveguide comprising a steel tube infilled with noisy granular material. The results provide unequivocal evidence that the sensor can detect and quantify acoustic emission generated through interaction of the steel tube and infill materials during deformation. Although absolute values are specific to the measurement system characteristics, AE rates are proportional to displacement rates with a strong correlation (e.g. $R^{2}$ values between 0.98 and 0.99 have been obtained for the range of tests presented). A group of granular materials (i.e. sands and crushed glass) have been shown to generate comparable rates of $\mathrm{AE}$, thus providing confidence that local materials could be used to construct waveguides at a site and generate equivalent $\mathrm{AE}$ behaviour as obtained in this laboratory study.

An approach has been described to select a threshold $\mathrm{AE}$ rate signature that can be used to generate an alert message to the community. This is based on knowledge that slope displacements accelerate in first-time failures. A threshold slope displacement rate in the range 5 to $10 \mathrm{~mm} / \mathrm{min}$ (i.e. Moderate rate) is proposed, with an equivalent $\mathrm{AE}$ threshold rate derived for the specific sensor and waveguide configuration used. It has been shown that larger diameters of waveguides with infill generate significantly higher levels of $\mathrm{AE}$ when deformed; however, the diameter must be optimised to also consider the requirements for installation (i.e. small diameter tubes are easier to drive into the ground). The next step is to conduct field trials of the CSS approach in conditions typical for future applications, and therefore, a field trial is in progress with partners in Malaysia, including a community group, and further trials are being planned. This novel low-cost monitoring approach could be used as part of an EWS to help protect vulnerable communities around the world from landslide hazards and ultimately save lives.

\section{Acknowledgements}

The research to develop and asses the Community Slope SAFE approach was funded by the UK Engineering and Physical Sciences Research Council through Loughborough University Institutional Sponsorship (EP/P510828/1) and a series of Enterprise Group Impact Acceleration Account awards. Smith gratefully acknowledges the support of an EPSRC Fellowship (EP/Po12493/1). Special thanks are due to Datalink Electronics Ltd. who carried out the CSS MP sensor development for low-cost manufacture, to Lewis Darwin, technician, for supporting the laboratory trials and to undergraduate Bethan Ivory who conducted laboratory trials of the first CSS HPP sensor.

Open Access This article is distributed under the terms of the Creative Commons Attribution 4.0 International License (http:// creativecommons.org/licenses/by/4.o/), which permits unrestricted use, distribution, and reproduction in any medium, provided you give appropriate credit to the original author(s) and the source, provide a link to the Creative Commons license, and indicate if changes were made.

\section{References}

Berg N, Smith A, Russell S, Dixon N, Proudfoot D, Take A (2018) Correlation of acoustic emissions with patterns of movement in an extremely slow moving landslide at Peace River, Alberta, Canada. Can Geotech J. https://doi.org/10.1139/cgj-2016-0668

Chichibu A, Jo K, Nakamura M, Goto T, Kamata M (1989) Acoustic emission characteristics of unstable slopes. J Acoustic Emission 8(4):107-112

Cooper MR, Bromhead EN, Petley DJ, Grants DI (1998) The Selborne cutting stability experiment. Géotechnique 48(1):83-101

Cruden DM, Varnes DJ (1996) Landslide types and processes. In Landslides: investigation and mitigation (eds AK Turner and LR Schuster), TRB special report 247, Ch. 3. Washington, DC, USA: Transportation Research Board

Dixon N, Spriggs MP, Smith A, Meldrum P, Haslam E (2015a) Quantification of reactivated landslide behaviour using acoustic emission monitoring. Landslides 12(3):549-560 
Dixon N, Smith A, Spriggs MP, Ridley A, Meldrum P, Haslam E (2015b) Stability monitoring of a rail slope using acoustic emission. Proc Inst Civ Eng Geotech Eng 168(5):373-384

Emergency Management Australia (2001) Guide 8-reducing the community impact of landslides. Australian Emergency Manuals Series, part III emergency management practice, Volume 3 - Guidelines

EN10217-1 (2005) Welded steel tubes for pressure purposes-technical delivery conditions-part 1: non-alloy steel tubes with specified room temperature properties

EN10255 (2004) Non-alloy steel tubes suitable for welding and threading-technical delivery conditions

Fujiwara T, Ishibashi A, Monma K (1999) Application of acoustic emission method to Shirasu slope monitoring. In Slope stability engineering (Yagi, Yamagami \& Jiang (eds)). Rotterdam: Balkema, pp. 147-150

Hungr 0, Leroueil S, Picarelli L (2014) The Varnes classification of landslide types, an update. Landslides 11(2):167-194

Jakob M, Owen T, Simpson T (2012) A regional real-time debris-flow warning system for the district of North Vancouver, Canada. Landslides 9(2):165-178

Kjekstad 0, Highland L (2009) Economic and social impacts of landslides. In: Sassa K Canuti P (eds) Landslides - Disaster Risk Reduction, Springer-Verlag, Berlin Heidelberg

Koerner RM, McCabe WM, Lord AE (1981) Acoustic emission behaviour and monitoring of soils. In: Acoustic emission in geotechnical practice, ASTM STP 750, pp 93-141

Lagomarsino D, Segoni S, Fanti R, Catani F (2013) Updating and tuning a regional-scale landslide early warning system. Landslides 10(1):91-97

Leroueil S (2001) Natural slopes and cuts: movement and failure mechanisms. Géotechnique 51(3):197-243

Martelloni G, Segoni S, Fanti R, Catani F (2012) Rainfall thresholds for the forecasting of landslide occurrence at regional scale. Landslides 9(4):485-495

Michlmayr G, Chalari A, Clarke A, Or D (2017) Fiber-optic high-resolution acoustic emission (AE) monitoring of slope failure. Landslides 14(3):1139-1146

Nakajima I, Negishi M, Ujihira M, Tanabe T (1991) Application of the acoustic emission monitoring rod to landslide measurement. Proc 5th Conf. on Acoustic Emission/ Microseismic Activity in Geologic Structures and Materials, Pennsylvania, pp. 1-15

Petley D (2012) Global patterns of loss of life from landslides. Geology 40(10):927-930

Petley DN, Higuchi T, Petley DJ, Bulmer MH, Carey J (2005) Development of progressive landslide failure in cohesive materials. Geology 33(3):201-204

Saito M (1980) Semi-logarithmic representation for forecasting slope failure, in Proceedings, International Symposium on Landslides, volume 1: Meerut, India, Sarita Prakashan, p. 321-324

Sassa K, Wang G, Wang F, Wang Y, Tian Y (2005) Landslide risk assessment and disaster Management in the Imperial Resort Palace of Lishan, Xian, China (C101-4). In: Sassa K, Fukuoka H, Wang F, Wang G (eds) Landslides Risk Analysis and Sustainable Disaster Management. Springer, Berlin Heidelberg, pp 88-89

Smethurst JA, Smith A, Uhlemann S, Wooff C, Chambers J, Hughes P, Lenart S, Springman SM, Lofroth $H$, Hughes D (2017) Current and future role of instrumentation and monitoring in the performance of transport infrastructure slopes. Q J Eng Geol Hydrogeol 50:271-286. https://doi.org/10.1144/qjegh2016-080
Smith A, Dixon N (2015) Quantification of landslide velocity from active waveguidegenerated acoustic emission. Can Geotech J 52(4):413-425

Smith A, Dixon N, Meldrum P, Haslam E, Chambers J (2014) Acoustic emission monitoring of a soil slope: comparisons with continuous deformation measurements. Géotech Lett 4(4):255-261

Smith A, Dixon N, Fowmes GJ (2017a) Early detection of first-time slope failures using acoustic emission measurements: large-scale physical modelling. Géotechnique 67(2):138-152

Smith A, Dixon N, Fowmes GJ (2017b) Monitoring buried pipe deformation using acoustic emission: quantification of attenuation. Int J Geotech Eng 11(4):418-430

Smith A, Dixon N, Moore R, Meldrum P (2017c) Photographic feature: acoustic emission monitoring of coastal slopes in NE England, UK. Q J Eng Geol Hydrogeol. 2016-081

Stähli M, Sättele M, Huggel C, McArdell BW, Lehmann P, Van Herwijnen A, Berne A, Schleiss M, Ferrari A, Kos A, Or D (2015) Monitoring and prediction in early warning systems for rapid mass movements. Nat Hazards Earth Syst Sci 15(4):905-917

Uhlemann S, Smith A, Chambers J, Dixon N, Meldrum P, Dijkstra T, Haslam E, Merritt A, Gunn D (2016) Assessment of ground-based monitoring techniques applied to landslide investigations. Geomorphology 253(1):438-451

UNEP (2012) Early warning systems: a state of the art analysis and future directions. Division of Early Warning and Assessment (DEWA), United Nations Environment Programme (UNEP), Nairobi, 2012

UNISDR (2007) Hyogo Framework for Action (HFA) 2005-2015: Building the Resilience of Nations and Communities to Disasters. United Nations International Strategy for Disaster Risk Reduction (UNISDR), Geneva, Switzerland, 28pp

UNISDR (2009) Terminology on disaster risk reduction, United Nation International Strategy for Disaster Reduction. United Nations International Strategy for Disaster Reduction (UNISDR), Geneva, Switzerland, 35 pp.

UNISDR (2015) Sendai framework for disaster risk reduction 2015-2030. United Nations International Strategy for Disaster Reduction (UNISDR), UNISDR/GE/2015 - ICLUX EN5000, 1st edition

United Nations Framework Convention on Climate Change (2017) India communitybased flood early-warning system. http://unfccc.int/secretariat/ momentum_for_change/items/8688.php (accessed 1/8/2017)

N. Dixon - A. Smith $(\bowtie) \cdot M$. Andjelkovic

School of Architecture, Building and Civil Engineering,

Loughborough University,

Loughborough, LE11 3TU, UK

Email: a.smith10@lboro.ac.uk

J. A. Flint · B. Clark

Wolfson School,

Loughborough University,

Leicestershire, UK 